\title{
Effect of preoperative fusidic acid on the normal eyelid and conjunctival bacterial flora
}

\author{
PETER B TAYLOR, KHALID F TABBARA, AND EILEEN M BURD \\ From the Department of Ophthalmology, College of Medicine, King Saud University and the King Khaled Eye \\ Specialist Hospital, Riyadh, Saudi Arabia
}

SUMmARY A randomised trial comparing the topical application of $1 \%$ fusidic acid with $0 \cdot 3 \%$ gentamicin solution in the reduction of the normal preoperative lid and conjunctival microbial flora was performed. Forty patients awaiting cataract surgery were randomly divided into two groups consisting of 20 patients each. The first group received a $1 \%$ microcrystalline suspension of fusidic acid, the second $0.3 \%$ gentamicin to the preoperative eye every two hours between 0600 and 2400 daily for 48 hours preoperatively. Cultures were obtained from both the lid margins and the conjunctival sac of both groups prior to antibiotic therapy and again in the operating theatre before surgery. Microbiological identification and colony counts were performed by standard laboratory methods. Staphylococcus epidermidis was the commonest micro-organism isolated. Statistical analysis revealed no significant differences in the ability of a $1 \%$ microcrystalline suspension of fusidic acid and $0.3 \%$ gentamicin in eliminating or reducing the normal preoperative conjunctival or lid flora.

Postoperative infections, especially endophthalmitis, are serious complications of intraocular surgery. The aetiological agents of postoperative infections are often introduced intraocularly from the patient's own normal eyelid and/or conjunctival bacterial flora during surgical manipulation. ${ }^{12}$ To minimise the risk of postoperative infections prophylactic topical antimicrobial therapy is usually administered prior to intraocular surgery.

Bactericidal antibiotics are usually preferred for use in prophylaxis. To ensure protection from both Gram-positive and Gram-negative micro-organisms a broad-spectrum antibiotic such as gentamicin or erythromycin, or a combination of bacitracin and polymyxin, are frequently used in prophylaxis. The choice of a topical prophylactic antibiotic should be based on its efficacy against the causative agent, its low toxicity, low risk of systemic sensitisation, and reasonable cost.

It has been well established that Gram-positive organisms, particularly staphylococci, are the main constituents of the normal ocular flora and are also the predominant cause of postoperative infections. ${ }^{2}$ Fusidic acid (Fucidin) is a steroidal antibiotic isolated

Correspondence to Khalid F Tabbara, MD, King Khaled Eye Specialist Hospital, PO Box 7191, Riyadh 11462, Saudi Arabia. from the fermentation products of the fungus Fusidium coccineum. It is chemically related to cephalosporin $\mathbf{P}$, but it has no cross-reactivity with any other commonly used antibiotics. Fusidic acid was introduced in Europe in 1962 and has been effective against a wide range of Gram-positive organisms, with low activity against Gram-negative organisms and fungi, in the concentration range of the relatively low blood levels acquired with the recommended systemic doses. ${ }^{3}$ It has the greatest antistaphylococcal (both $\beta$ lactamase positive and negative) activity of any antimicrobial agent currently available. ${ }^{46}$

The topical ophthalmic fusidic acid preparation (Fucithalmic) would be expected to be effective against a wide range of Gram-positive organisms $\mathrm{s}^{347}$ and some Gram-negative organisms $s^{3+8}$ in view of its minimal inhibitory and minimal bactericidal concentrations. Fusidic acid can penetrate avascular tissue even in large collections of pus. ${ }^{910}$ The topical preparation has little or no epithelial toxicity and covers organisms such as Streptococcus spp. that are missed by other traditionally used prophylactic aminoglycosides. The following trial was undertaken to compare the efficacy of Fucithalmic with gentamicin in the preoperative prophylactic reduction of ocular flora. 


\section{Material and methods}

To evaluate the potential use of fusidic acid for prophýlaxis prior to intraocular surgery 40 consecutive patients awaiting cataract surgery were randomly divided into two groups of 20 patients each. The first group received topical $1 \%$ fusidic acid microcrystalline suspension (Fucithalmic) and the second group received $0.3 \%$ gentamicin ophthalmic solution in the preoperative eye. The drops were administered one drop every two hours beginning at 0600 until 2400 for 48 hours prior to surgery, the last dose being given at midnight the night before surgery. Phisohex face scrubs were given the evening before and again on the morning of surgery as part of the standard preoperative procedure.

To assess the antimicrobial effectiveness of the prophylactic medication cultures for bacteriological evaluation were taken before beginning prophylactic treatment and again in the operating room just prior to preparation for surgery. Cultures of the eyelids were obtained by rubbing a sterile cotton-tipped swab moistened in trypticase soy broth from the canthal eyelid margin of the lower eyelid to the temporal margin and back again. Conjunctival cultures were taken in a similar manner while pulling down on the lower eyelid with care to avoid the lid margins and lashes. The specimens were streaked on to $5 \%$ sheep blood agar and chocolate agar plates. Cultures were incubated at $37^{\circ} \mathrm{C}$ and observed at 24 and 48 hours.

The number of bacterial colonies growing were counted and quantitated with findings of less than 50 colonies graded as scant to light growth, 50 to 149 as moderate, and 150 or more as heavy growth. The bacteria were identified by standard bacteriological techniques. Antimicrobial sensitivity testing was done by the modified Kirby-Bauer disc diffusion method using Mueller Hinton agar. Statistical analysis of the data was performed by the Wilcoxon signed rank test and the binominal test for proportions to evaluate the significance of the results.

\section{Results}

\section{CONJUNCTIVA}

The cultures of the conjunctivae from 22 of the 40 patients $(55 \%)$ revealed moderate pretreatment growth of Staphylococcus epidermidis; six of 22 $(27 \%)$ had concomitant growth of other organisms. Of the mixed growth cultures, two included light growth of Corynebacterium species, one with light growth of a streptococcus (alphahemolytic), one with light to moderate growth of both Morganella morganii and Corynebacterium species, one with light growth of Staphylococcus aureus, and one had
Table 1 Conjunctival isolates from cultures taken before and after treatment with fusidic acid or gentamicin

\begin{tabular}{|c|c|c|c|c|}
\hline \multirow[t]{2}{*}{ Therapy } & \multicolumn{2}{|l|}{ Pretreatment } & \multicolumn{2}{|l|}{ Post-treatment } \\
\hline & $\begin{array}{l}\text { Staphylococcus } \\
\text { species }\end{array}$ & Other* & $\begin{array}{l}\text { Staphylococcus } \\
\text { species }\end{array}$ & Other \\
\hline Fusidic acid & $\begin{array}{l}13 / 20 \\
(65 \%)\end{array}$ & $\begin{array}{l}8 / 20 \\
(40 \%)\end{array}$ & $\begin{array}{l}1 / 20 \\
(5 \%)\end{array}$ & $\begin{array}{l}0 / 20 \\
(0 \%)\end{array}$ \\
\hline Gentamicin & $\begin{array}{l}9 / 20 \\
(45 \%)\end{array}$ & $\begin{array}{l}3 / 20 \\
(15 \%)\end{array}$ & $\begin{array}{l}1 / 20 \\
(5 \%)\end{array}$ & $\begin{array}{l}1 / 20 \\
(5 \%)\end{array}$ \\
\hline
\end{tabular}

* Other includes cultures with more than one organism isolated.

scant growth of Citrobacter diversus. Of the remaining 18 patients one had only light growth of Streptococcus acidominimus, one grew mixed scant to light Str. morbillorum and Corynebacterium species; 16 of the 40 patients $(40 \%)$ showed no growth prior to initiation of therapy.

Following treatment only one eye in each of the antibiotic treatment groups showed growth of Staphylococcus epidermidis. In both of these cases the organism was resistant to the antibiotic used for that eye. In the fusidic-acid-treated eyes the quantity of growth decreased from a pretreatment of light to a post-treatment of scant growth. In the gentamicintreated eye no organisms were found before treatment; but moderate growth of Staph. epidermidis was found after treatment. The other organisms (Corynebacterium and $M$. morganii) found before treatment in the patients using fusidic acid were completely eliminated, as were the organisms (Streptococcus species, Staph. aureus, and Citrobacter diversus) in the gentamicin-treated patients.

In one gentamicin-treated patient, however, cultures after treatment revealed 94 colonies of Micrococcus species resistant to gentamicin which were isolated from the eye of a pretreatmentnegative patient (Table 1).

\section{LID MARGINS}

The eyelids of all patients showed bacterial growth before treatment. Of the 40 eyes $37(93 \%)$ revealed moderate to heavy growth of Staphylococcus epidermidis. Of those with positive cultures for Staph. epidermidis $9(24 \%)$ had concomitant growth of other organisms. Of those eyelids giving a mixed growth one gave a moderate growth of $\boldsymbol{M}$. morganii and Corynebacterium species, one scant growth of Bacillus species, one scant to light growth of Klebsiella pneumoniae and Corynebacterium species, one moderate growth of Corynebacterium species, one moderate growth of $C$. diversus, one scant growth of Str. morbillorum, Enterobacter agglomerans, and heavy growth of Corynebacterium species, one moderate growth of Moraxella species, 
Table 2 Lid margin isolates from cultures taken before and after treatment with fusidic acid or gentamicin

\begin{tabular}{|c|c|c|c|c|c|c|c|c|}
\hline \multirow[t]{3}{*}{ Therapy } & \multicolumn{4}{|c|}{ Pretreatment } & \multirow{2}{*}{\multicolumn{3}{|c|}{$\begin{array}{l}\text { Post-treatment } \\
\text { Staphylococcus } \\
\text { species }\end{array}$}} & 、 \\
\hline & \multicolumn{3}{|c|}{$\begin{array}{l}\text { Staphylococcus } \\
\text { species }\end{array}$} & \multirow[t]{2}{*}{ Other* } & & & & Other* \\
\hline & $A$ & $B$ & $C+$ & & $A$ & $B$ & $C+$ & \\
\hline Fusidic acid & $\begin{array}{l}2 / 20 \\
(10 \%)\end{array}$ & $\begin{array}{l}2 / 20 \\
(10 \%)\end{array}$ & $\begin{array}{l}16 / 20 \\
(80 \%)\end{array}$ & $\begin{array}{l}4 / 20 \\
(20 \%)\end{array}$ & $\begin{array}{l}7 / 20 \\
(35 \%)\end{array}$ & $\begin{array}{l}0 / 20 \\
(0 \%)\end{array}$ & $\begin{array}{l}1 / 20 \\
(5 \%)\end{array}$ & $\begin{array}{l}0 / 20 \\
(0 \%)\end{array}$ \\
\hline Gentamicin & $\begin{array}{l}2 / 20 \\
(10 \%)\end{array}$ & $\begin{array}{l}8 / 20 \\
(40 \%)\end{array}$ & $\begin{array}{l}9 / 20 \\
(45 \%)\end{array}$ & $\begin{array}{l}6 / 20 \\
(30 \%)\end{array}$ & $\begin{array}{l}3 / 20 \\
(15 \%)\end{array}$ & $\begin{array}{l}1 / 20 \\
(5 \%)\end{array}$ & $\begin{array}{l}0 / 20 \\
(0 \%)\end{array}$ & $\begin{array}{l}1 / 20 \\
(5 \%)\end{array}$ \\
\hline
\end{tabular}

${ }^{*}$ Other includes those cultures with more than one organism isolated. $\dagger \mathrm{A}=$ colonies quantitated at scant to light growth (1-49 colonies).

$\mathrm{B}=$ moderate growth (50-149 colonies). $\mathrm{C}=$ heavy growth (150 colonies or more).

and two eyes gave scant and heavy growth of Staph. aureus. The lids of three of the 40 eyes $(7 \%)$ gave pure growths of other organisms, two with heavy growth of Staph. aureus and one with moderate to heavy mixed growth of Staph. acidominimus and Corynebacterium species.

Post-treatment lid margin cultures of those with pretreatment Staph. epidermidis showed complete elimination (no growth) in 10 of the $18(55 \%)$ patients receiving fusidic acid and in 15 of the 19 $(79 \%)$ receiving gentamicin. Of the remainder of those with post-treatment Staph. epidermidis, only 14 of the $37(38 \%)$ showed a significant reduction in growth quantity for the two different antibiotics (Table 2).

All other organisms found in pretreatment cultures were completely eliminated in cultures taken after treatment. However, in one patient receiving gentamicin a Micrococcus species resistant to gentamicin was isolated that was not present in pretreatment cultures.

Statistical analysis comparing pretreatment and post-treatment counts using Staphylococcus species growth as a sample showed significant reduction in bacterial flora for both conjunctiva and lid margins whether treated by fusidic acid or gentamicin (Tables 1 and 2) (conjunctiva: fusidic acid, $p=0.0005$, gentamicin, $p=0.0117$; lid margin: fusidic acid, $p=0.0001$, gentamicin, $p=0.0007)$. No significant differences (eyelids, $p=0 \cdot 478$; conjunctiva, $p=0.97$ ) were found when comparing post-treatment colony counts of fusidic-acid-treated versus gentamicintreated eyes.

\section{SUMMARY OF RESULTS}

In the present study fusidic acid either eliminated or reduced the colonies of Staph. epidermidis present in all but one of the eyes studied. The one case in which there was an increase in the number of Staph. epidermidis colonies along the lid margins involved a resistant strain. Resistance of Staph. epidermidis was found in $10.5 \%$ of gentamicin-treated eyes and $28 \%$ of Fucithalmic-treated eyes. One lid margin was found to have heavy growth of resistant Staph. aureus organisms that were completely eliminated by topical Fucithalmic. Other bacteria, including $\alpha$-haemolytic streptococcus, Bacillus spp, Klebsiella pneumoniae, and Morganella morganii which demonstrated resistance in vitro were eliminated from the eyelids and conjunctiva by Fucithalmic. Resistance testing in vitro is based on projected serum levels achieved by systemic antibiotic administration and frequently does not correlate with susceptibility of the organism to topically applied drugs. However, such testing provides useful information on the antibiotic to which the organism is most sensitive. Corynebacterium spp. were also eliminated, though susceptibility testing in vitro was not performed.

\section{Discussion}

The choice of antibiotic to be used for prevention of postsurgical infections should be based on knowledge of the bacteria usually involved and their general patterns of susceptibility to antibiotics. This knowledge is difficult for any one institution to have because of the relatively few cases encountered; we therefore depend on reports of retrospective studies for such information. Many of the early series reporting postoperative ocular infections did not mention the causative organisms or implicated organisms from improperly sterilised surgical instruments, contaminated solutions, or bacteria from skin or nasal mucosa of surgeon or operating room staff. With improvements in sterile technique, sterilisation of surgical instruments, and strict quality control of solutions and medications, the normal ocular flora have been implicated as the source of postoperative infection in most cases ${ }^{11-13}$ and bacteriophage typing of strains has confirmed this suspicion in one study. ${ }^{14}$

Antibiotics used topically as prophylaxis before 
intraocular surgery do not always completely eradicate the indigenous eyelid and conjunctival flora. ${ }^{15 / 6}$ However, a review of the literature clearly shows that the incidence of postsurgical endophthalmitis was markedly reduced from an average of $1.3 \%$ (range, $0.44 \%$ to $3 \cdot 16 \%$ ) in patients not given prophylactic antibiotics, to an average of $0.335 \%$ (range, $0.00 \%$ to $0.57 \%$ ) in patients who did receive prophylactic antibiotics. $^{2}$

The organisms most commonly recovered in cases of postsurgical endophthalmitis include primarily Staph. aureus and Staph. epidermidis. Streptococcus spp., Proteus spp., and Pseudomonas spp. are also commonly seen, although less frequently. ${ }^{11-14} 17$

Studies of the efficacy of topical antibiotics in reducing normal ocular bacterial flora have shown that antibiotics vary widely in their ability to reduce or eliminate the normal ocular flora. Although various dosage schedules were used, the superiority of gentamicin $\mathbf{0 . 3 \%}$ solution over the following other agents has been clearly demonstrated: chloramphenicol $0.5 \%$ solution; ${ }^{118}{ }^{19}$ sulphacethamide $30 \%$ solution; ${ }^{20}$ sulphametiazole $4 \%$ solution; bacitracin $1 \%$-neomycin $0.5 \%$ solution; neomycin-polymyxinB-gramicidin solution; ristocetin sulphate $0.5 \%$ polymyxin B $0.25 \%$ solution; oxytetracycline chloride $3 \%$-polymyxin B $0 \cdot 1 \%$ ointment; ${ }^{16}$ soframycin $0.5 \%$ solution; and sodium sulphate $10 \%$ solution. ${ }^{19}$ In addition, gentamicin $0.3 \%$ ointment was as effective as gentamicin $0.3 \%$ solution in one study. ${ }^{18}$ Gentamicin is an antibiotic whose antibacterial spectrum includes most normal ocular flora, particularly staphylococci.

The present study showed that fusidic acid 1\% microcyrstalline suspension was as effective as gentamicin in reducing or eliminating Staph. epidermidis present on the lid margin or in the conjunctival fornix of presurgical cataract patients when administered every two hours from 0600 to 2400 for 48 hours prior to surgery. Fusidic acid applied topically penetrates the cornea well (Taylor and colleagues, unpublished data) and is bactericidal in concentrations close to the minimal inhibitory concentration. When topically applied, this microcrystalline suspension of fusidic acid is effective against most Gram-positive bacteria such as Streptococcus spp. which can be missed by more traditional preoperative aminoglycoside therapy. This antibiotic may provide another alterna- tive in preoperative prophylactic antimicrobial therapy.

The topical fusidic acid $1 \%$ viscodrops were kindly supplied by Leo Pharmaceuticals Ltd, Denmark.

We thank Robert L Phillips, PhD, and William Greer, PhD, of King Faisal Specialist Hospital and Research Centre for the help with statistical analysis of the data.

\section{References}

1 Debnath SC, Talukder MAS, Bartlett FW. Effect of preoperative antibiotics on bacterial colony counts of the conjunctival sac. J Ocul Ther Surg 1985; 4: 122-4.

2 Starr MB. Prophylactic antibiotics for ophthalmic surgery. Surv Ophthalmol 1983; 27: 353-73.

3 Godtfredson WO, Roholt K, Tybring L. Fucidin: a new orally active antibiotic. Lancet 1962, ii: 137-48.

4 Barber M, Waterworth P. Antibacterial activity in vitro of fucidin. Lancet 1962; i: 931-2.

5 Newmann RL, Bhat KM. Hackney R, et al. Fusidic acid: laboratory and clinical assessment. Br Med J 1962; ii: 1645-7.

6 King K, Brady LM, Harkness JL. Gentamicin-resistant staphylococci. Lancet 1981; ii: 698-9.

7 Tabbara KF, Lawson NA, Burd EM. In vitro susceptibility to fusidic acid of clinically significant isolates from ocular infections. Saudi Med J 1987; 8(2): 167-70.

8 Jacobsen J. The sensitivity of eye pathogenic bacteria towards fucidin, chloramphenicol, and tetracycline given as MIC values. Bacteriologic Department, Leo Pharmaceuticals Ltd: May 1980.

9 Taylor G, Bloor K. Antistaphylococcal activity of fucidin. Lancet 1962; i: 935-7.

10 Crosbie RB. Treatment of staphylococcal infections with Fucidin. Br Med J 1963; i: 788-94.

11 Valenton MJ, Brubaker RF, Allen HF. Staphylococcus epidermidis (albus) endophthalmitis. Arch Ophthalmol 1973; 89: 94-6.

12 Baum JL, Rao G. Treatment of post-cataract endophthalmitis with periocular and systemic antibiotics and corticosteroids. Ophthalmology 1976; 81: 151-7.

13 Forster RK, Abbott RL, Gelender H. Management of infectious endophthalmitis. Ophthalmology 1980; 87: 313-8.

14 Locatcher-Khorazo D, Sullivan N, Gutierrez E. Staphylococcus aureus isolated from normal and infected eyes. Arch Ophthalmol 1967; 77: 370-7.

15 Whitney CR, Anderson RP, Allansmith MR. Preoperatively administered antibiotics: their effect on bacteria counts of the eyelids. Arch Ophthalmol 1972; 87: 155-60.

16 Fahmy JA. Bacterial flora in relation to cataract extraction: V. Effects of topical antibiotics on the preoperative conjunctival flora. Acta Ophthalmol (Kbh) 1980; 58: 567-75.

17 Allen HF, Mangiaracine AB. Bacterial endophthalmitis after cataract extraction: II. Incidence in 36000 consecutive operations with special reference to preoperative topical antibiotics. Arch Ophthalmol 1974; 91: 3-7.

18 Burns RP, Oden M. Antibiotic prophylaxis in cataract surgery. Trans Am Ophthalmol Soc 1972; 70: 43-57.

19 Burns RP. Effectiveness study of antibiotics. In: Leopold IH, ed. Symposium on ocular therapy St Louis: Mosby, 1972; 5: 105-12.

Accepted for publication 8 January 1987. 